\title{
Adolescencia y felicidad
}

\section{Adolescence and happiness}

\author{
Paulina M. Merino-Osorio* \\ Instituto de Investigaciones Maternoinfantil, Universidad de Chile, Santiago de Chile, Chile
}

La semana pasada, esperando inspirarme para escribir este editorial, me vi en dos situaciones, en días seguidos. La primera, una tarde tomando un café con una amiga profesora de octavo básico, me comentó lo preocupada que estaba por poder acompañar a sus alumnas en «los cambios actuales», y terminamos conversando de lo entretenidas e idealistas que son y de lo necesitadas que están de que alguien las acoja. Al día siguiente, me encontré con una colega que me comentó que me había derivado a dos adolescentes "porque a esta edad están tooooodas con problemas», haciendo un gesto de desesperación. Los días siguientes me quedé pensando en cómo ambas profesionales se sienten, en diferentes niveles, preocupadas o abrumadas ante las niñas que crecen. Parece que el «sufrimiento" que socialmente se ha asociado (a mi parecer erróneamente) a esta etapa de la vida les toca también a los adultos que acompañan a las niñas que transitan a la adultez. Recordemos que el concepto «adolescencia» no viene de «adolecer», que significa caer enfermo o padecer una dolencia. Etimológicamente proviene del verbo latino adolescere, que significa "crecer, desarrollarse». La transición biológica, social y psicológica que ocurre en esta etapa tan amplia que es la adolescencia (10 a 19 años) representa una gran tarea para las niñas, sus familias y todos los profesionales que las acompañamos.

Ahora, ¿cuál es el interés común de todos los «adultos acompañantes»? ¿La prevención de conductas de riesgo? ¿La reducción del embarazo adolescente?
Personalmente (y como madre de dos niñas), creo que lo que todos queremos lograr es que la adolescente llegue a ser una mujer feliz.

Para los jóvenes de hoy, ¿cuáles son las condiciones más importantes para ser feliz en la vida? En la Encuesta Nacional del Instituto Nacional de la Juventud (INJUV) se ha realizado esta pregunta desde el año 2012. Ese año, un $32 \%$ de los encuestados declaraba que para ser feliz había que «tener un trabajo o profesión que le gustara», un $27 \%$ "construir una buena familia o relación de pareja» y un 16\% «desarrollarme como persona». En el año 2018, este último punto superó con un $32 \%$ al $24 \%$ de la aspiración de desarrollo profesional y al $21 \%$ de la construcción de una familia o relación de pareja 1 .

Ahora el desafío: ¿cómo logramos que la adolescente logre desarrollarse como persona, que es lo primero y más básico para poder ser una buena profesional y lograr formar una buena familia o relación de pareja? Mi respuesta: trabajando para que tenga una adolescencia sana y feliz, un espacio para ir cumpliendo las tareas evolutivas que le permitan ser una mujer independiente emocionalmente, que se sienta querida y se quiera a sí misma, que se sienta hija y logre luego ser madre, cuando ella lo desee y si así lo desea (en los amplios aspectos que tiene la maternidad: biológicos, espirituales, etc.).

Uno de los principales aspectos que preocupa a padres, educadores y personal de salud es que la adolescente que se enfrenta a un inicio precoz de la
Disponible en internet: 27-10-2021 Rev Chil Obstet Ginecol. 2021;86(4):345-346 www.rechog.com 0048-766X / @ 2021 Sociedad Chilena de Obstetricia y Ginecología. Publicado por Permanyer. Éste es un artículo open access bajo la licencia CC BY-NC-ND (https://creativecommons.org/licenses/by-nc-nd/4.0/). 
actividad sexual, sin protección anticonceptiva y con múltiples parejas sexuales, se puede exponer a un embarazo, infecciones de transmisión sexual y violencia sexual; situaciones que pueden retrasar o dificultar lograr las "condiciones para ser feliz".

El embarazo adolescente es un problema de salud pública. Corresponde al $10 \%$ de los embarazos, con un $25 \%$ de morbimortalidad materna y perinatal, y un gran costo social de deserción escolar ${ }^{2}$. En general, la prevención del embarazo ha estado en la línea de la provisión de métodos anticonceptivos efectivos. El American College of Obstetricians and Gynecologists y la American Academy of Pediatrics han recomendado como primera línea los anticonceptivos reversibles de larga duración en adolescentes y jóvenes ${ }^{3-6}$. Según una revisión Cochrane ${ }^{7}$, las intervenciones que combinan la entrega del anticonceptivo con la consejería en sexualidad son las más eficaces para reducir los embarazos adolescentes no planificados. Por ello, una consejería integral que promueva la postergación en las adolescentes que no tienen intención de iniciar su vida sexual y que entreguen herramientas efectivas para la prevención del embarazo a las que quieren tener una sexualidad segura es tarea primordial del equipo de salud ${ }^{8}$. Lamentablemente, no existen en Chile datos publicados sobre los resultados de estas acciones combinadas, que sabemos que se implementan en espacios amigables hace varios años y que a muchos de nosotros nos enseñan y enseñamos en pregrado y posgrado.

En esta edición, Leal y Molina nos muestran los cambios en el uso de anticonceptivos y el número de embarazos no planificados y de hijos en adolescentes chilenas entre los años 1997 y 2018. Utilizaron las bases de datos de acceso público de la segunda (1997) a la novena (2018) encuestas nacionales del INJUV, tomando para su estudio los resultados de las adolescentes de 15 a 19 años. Observaron que los embarazos no planificados y tener hijos tuvieron una tendencia decreciente, disminuyendo un $4,78 \%$ y un $3,93 \%$, respectivamente, cada 3 años. El uso de anticonceptivos tuvo una tendencia creciente, aumentando un 4,59\% cada 3 años, especialmente los métodos efectivos de corta duración, como inyectables y píldoras. El mayor aumento del uso se observó después del año 2012, a los 2 años de que se promulgara la Ley 20.418 que fija las normas sobre información, orientación y prestaciones de salud en materia de regulación de la fertilidad, que obligó a resguardar la confidencialidad en la atención de salud sexual y reproductiva en adolescentes a partir de los 14 años. Esta ley permitió que adolescentes competentes y responsables acudieran a los servicios de salud por la entrega de un método anticonceptivo, sin la necesidad de concurrir una persona adulta ${ }^{9}$. Probablemente, el menor acceso a los anticonceptivos más efectivos se debería a barreras en el acceso a ellos, ya sea por la necesidad de tener un proveedor de salud capacitado para su inserción, los mayores costos iniciales o las creencias y mitos relativos al uso del dispositivo intrauterino en las nulíparas. Por fortuna, existen estrategias locales que buscan prevenir el embarazo reiterado en adolescentes con el uso de anticonceptivos reversibles de larga duración en el posparto inmediato ${ }^{10}$.

Yo les invito, en este tiempo de «distancia social», a volver a crear comunidad, a formar y fortalecer los vínculos entre el equipo de salud, los padres, los profesores y los adolescentes. Les invito a perder el miedo a las dificultades y al dolor, y a trabajar por ser profesionales integrales y referentes para nuestras adolescentes. Les invito a reconocer las limitaciones y a derivar si es que no se sienten preparados para acoger, escuchar, aconsejar y cuidar. ¡Pues todos nosotros también queremos ser felices! Y acá vuelve la pregunta: ¿qué es la felicidad? Como dijo alguien sabio por ahí: «es tener un proyecto en la vida y trabajar para cumplirlo». Continuemos con «nuestro proyecto» y ayudemos a las adolescentes a "descubrir el suyo para su desarrollo personal», aceptemos los «dolores del crecimiento» y afrontemos el futuro con una mirada esperanzadora.

Con cariño,

Paulina

\section{Bibliografía}

1. Novena Encuesta Nacional del INJUV. Disponible en: https://www.injuv. gob.cl/9encuesta

2. Leftwich HK, Alves MV. Adolescent pregnancy. Pediatr Clin North Am. 2017;64:381-8.

3. Committee on Adolescent Health Care Long-Acting Reversible Contraception Working Group. Committee opinion no. 539: adolescents and long-acting reversible contraception: implants and intrauterine devices. Obstet Gynecol. 2012;120:983-8.

4. Yen S, Martin S. Contraception for adolescents. Pediatr Ann. 2013;42:21-5.

5. Kavanaugh ML, Frohwirth L, Jerman J, Popkin R, Ethier K. Long-acting reversible contraception for adolescents and young adults: patient and provider perspectives. J Pediatr Adolesc Gynecol. 2013;26:86-95.

6. American Academy of Pediatrics Committee on Adolescence, Blythe MJ, Diaz A. Contraception and adolescents. Pediatrics. 2007;120:1135-48.

7. Oringanje C, Meremikwu MM, Eko H, Esu E, Meremikwu A, Ehiri JE. Interventions for preventing unintended pregnancies among adolescents. Cochrane Database Syst Rev. 2009;(4):CD005215.

8. Cannoni G, González M, Conejero C, Merino PM, Schulin-Zeuthen C. Sexualidad en la adolescente: consejería. Rev Med Clin Condes. 2015;26:81-7.

9. Ley 20.418. Fija Normas sobre Información, Orientación y Prestaciones en Materia de Regulación de la Fertilidad. Biblioteca del Congreso Nacional (28-01-2010). [Consultado el 5 de mayo de 2012]. Disponible en: http://www.leychile.cl/Navegar?;dNorma $=\mid$ 0104828ddParte=8ddVersjon=2010-01-28

10. Von Hoveling A, Larrea E, Norambuena C, Carrasco L. Prevención del embarazo reiterado en adolescentes: una experiencia clínica exitosa. Rev Chil Obstet Ginecol. 2020;85:631-40. 